\title{
Chronic Lyme Disease Complex and Its Commonly Undiagnosed Primary and Secondary Co-Infections
}

\author{
Aaron Smith, John Oertle, Dan Warren, Dino Prato \\ Envita, Scottsdale, AZ, USA \\ Email: Aaron@envita.com, JohnO@envita.com, DanW@envita.com, DinoPrato@envita.com
}

Received 16 July 2015; accepted 21 September 2015; published 24 September 2015

Copyright (C) 2015 by authors and Scientific Research Publishing Inc.

This work is licensed under the Creative Commons Attribution International License (CC BY). http://creativecommons.org/licenses/by/4.0/

(c) (i) Open Access

\begin{abstract}
Chronic Lyme disease complex describes the burden carried by patients infected with Borrelia burgdorferi as well as other co-infections or secondary co-infections (opportunistic infections). These infections can cause a significant burden on patients more so than Lyme disease alone. Along with the many underdiagnosed cases of Lyme disease throughout the world exists numerous undiagnosed co-infection and secondary co-infections leading to debilitating symptoms for many patients. The potential for co-infections varies by location as well as to the exposure to various species of ticks. Since there is potential for patients to experience several tick bites including those of different species, additional microorganisms also commonly transmitted via tick bite are included that are typically left out of the conversation of potential Borrelia burgdorferi co-infections. The most common co-infections of Lyme disease include anaplasmosis, babasiosis, bartonellosis and ehrlichiosis. Secondary co-infections or opportunistic infections commonly seen in patients with Lyme disease are also discussed. By helping to establish a comprehensive list of infections associated with Chronic Lyme disease complex may in fact help patients receive a proper diagnosis in order to administer the much needed comprehensive treatments patients deserve.
\end{abstract}

\section{Keywords}

Lyme, Anaplasmosis, Babasiosis, Bartonellosis, Ehrlichiosis, Co-Infections, Opportunistic Infection

\section{Introduction}

Lyme disease is caused by an infection of the spirochete Borrelia burgdorferi and is transmitted via Ixode tick bite. Transmission of other infections that are also commonly associated with tick bites has the potential to cause co-occurring infections with Lyme disease which if untreated can lead to what we call Chronic Lyme disease 
complex. Other opportunistic infections can become more pronounced during the stages of a chronic Lyme infection. Co-infections and opportunistic infections have the potential to complicate the treatment of chronic Lyme disease thus leading to more rigorous treatment regimens and potentially longer duration of illness. Although certain co-infections are more likely to occur via prevalence in ticks in certain geographical areas, it is important to recognize that chronic Lyme disease complex is common among those infected with Borrelia and therefore should be considered when treating chronic Lyme disease patients. Other diseases harbored by ticks that are not known to carry Lyme disease are included as potential co-infections since there is potential for multiple tick bites. Although the likelihood of some of these tick-borne infections to co-occur with Lyme disease is low, it is important to recognize all of the potential for co-infections as well as raise awareness of other possible tick infections.

\section{Co-Infections Associated with Lyme Disease Complex}

The following tick borne infections are not listed in order of prevalence of co-occurring with Lyme disease but instead are listed in alphabetical order. These tick infections range in severity and treatability and can be exacerbated by the immunocompromised state of individuals suffering from chronic Lyme disease complex. Research conducted on each of these co-infecting microorganisms varies in size and scope with Powassan virus being the least studied as well as the least common infection.

\subsection{Anaplasmosis}

Human granulocytotropic anaplasmosis (HGA) caused by Anaplasma phagocytophilum is spread by tick vector particularly in the eastern and midwestern regions of the United States. Cross sectional analysis shows a seroprevalence as high as $14.9 \%$ in Wisconsin [1].

The most common manifestation of symptoms include nonspecific fever, myalgia, chills, and headache [2]-[6]. Other complications can include toxic shock-like syndrome, invasive opportunistic infections of fungal and viral infections, respiratory insufficiencies, pancarditis, hemorrhage, neurologic diseases including demyelinating polyneuropathy and brachial plexopathy, acute renal failure, and rhabdomyolysis [7]-[10]. Asymptomatic presentation is possible while other infections can be fatal with an increase severity associated with a patient's age and comorbid illness [11]. The severity of HGA varies with almost half of patients requiring hospitalization and $17 \%$ of patients requiring admission to an intensive care unit [5]. Common incubation period before the presentation of symptoms is between one to two weeks.

Blood smear examination and PCR analysis during infection or serologic testing in late stage infections are the primary means of diagnosis of HGA. Blood samples should be taken prior to antibiotic treatment since the antibiotics can rapidly reduce the detectable quantities of both infected cells and bacterial DNA. Indirect fluorescent antibody method is the primary means of detecting Anaplasma phagocytophilum in serological testing.

The traditional agent of choice to treat Anaplasma phagocytophilum is doxycycline as compared with other tretracycline derivatives. Tretracyline has demonstrated usefulness in vitro for both Ehrlichia and Anaplasma [12]-[14]. In the absence of contraindication to tetracycline drugs, patients should be treated with intravenous (IV) or oral tetracycline. The recommended regimen for adults is $100 \mathrm{mg}$ orally twice a day with clinical improvements expressed within one or two days of treatment [15]-[20]. Patients that do not respond within this time frame should be reevaluated for either alternative treatment or diagnosis.

\subsection{Babesisa}

Babesiosis is caused by an infection of either Babesiadivergens or Babesia microti via a tick-borne vector. They are the only protozoan tick-borne vector in the United States. The majority of the cases of babesiosis occur in the northeastern United States.

Influenza like symptoms are common one week after inoculation of either Babesiadivergens or Babesia microti. Other symptoms that might occur are fever, myalgias, sweating, and headache. High fever, hemoglobinuria, renal failure, jaundice, and hemolytic anemia makes babesiosis resemble falciparum malaria. There is also a chance that the disease can persist asymptomatically in younger adults.

Detection of protozoa in the blood stream is the primary means of diagnosing babesiosis. Other available testing includes polymerase chain reaction (PCR) and serological tests. Appropriate exposure history, fever, and hemolytic anemia is an indicator of babesiosis. 
For those experiencing mild symptoms, a symptomatic approach might be the best course of treatment. 650 $\mathrm{mg}$ of Quinine (Quinamm) given three times a day orally for seven days in addition to $600 \mathrm{mg}$ of clindamycin (Cleocin) three times a day for seven to ten days should be administered to patients with more pronounced symptoms. $750 \mathrm{mg}$ of atovaquone (Mepron) given twice per day for seven to ten days with $600 \mathrm{mg}$ of azithromycin (Zithromax) orally once per day for seven to 10 days is another method of treating babesiosis. It is important to note that reduced dosing is necessary for children. Severely ill patients with high parasitemia have undergone exchange transfusion.

\subsection{Bartonella}

Bartonella infections are more commonly known as cat-scratch disease (CSD). The infection is caused by ticks and has been reported in all areas of the continental United States but occurs more often in northern states. August through October are when the disease incidence increases and is primarily found in humid and warm locations.

Although adults can contract CSD, children are more likely to contract the disease. Lymphadenopathy is common in $85 \%$ - $90 \%$ of patients with CSD [21]. At the site of inoculation, a primary skin lesion will begin to appear with few patients not exhibiting this symptom. Lymph nodes swelling is common with the infection and patients may also experience tender lymph nodes which may eventually suppurate [22]. Patients are $75 \%$ likely to develop aching, anorexia, and malaise with only $9 \%$ experiencing a low grade fever [22]. Myalgia, arthritis, and arthralgia are common musculoskeletal problems that occur in $10 \%$ of patients.

Lymph node biopsies are necessary for patients with failing lymph nodes and whose diagnosis is uncertain. Stellate granulomas and lymphoid hyperplasia are seen in patients with CSD. Bacterial stains using silver and the morphology of $B$. henselae, which is a small, curved, and aerobic gram-negative bacteria, is necessary for its identification. With those confirmed to have CSD, it is important for doctors to follow up who have unilateral lymphadenopathy [22].

A study evaluating CSD in 1200 patients with lymphadenopathy showed that antibiotics were rarely used on patients [23]. The most common form of treatment involves the use of azithromycin (Zithromax) prescribed in dosages of $500 \mathrm{mg}$ on the first day and $250 \mathrm{mg}$ for the next four days in patients with CSD. 30 days after treatment with azithromycin showed that $57 \%$ of patients experienced $80 \%$ resolution at day 30 as compared to placebo where only $6.7 \%$ of patients experienced that level of remission [24]. Ciproflaxacin (Cipro), rifampin, gentamicibin, and trimethoprim/sulfamethozazole (Bactim, Septra) have been used to treat CSD [25].

\subsection{Colorado Tick Fever}

Coltivirus is an RNA orbivirus transmitted by a tick that causes Colorado tick fever. In the Rocky Mountain region, approximately 200 to 300 cases are reported each year. Colorado tick fever often goes unnoticed due to its benign presentation and therefore goes undetected which suggests the annual incidence could be much higher [26]. Increased risk of severe complications occurs in the immunocompromised and those that have undergone a splenectomy.

Seven days after inoculation, influenza-like symptoms begin. It is rare to have respiratory issues after contracting Colorado tick fever even though nearly one third of patients get a sore throat [2]. Rash, conjunctivitis, and meningitis are the most significant biphasic symptoms with fever. Seven to ten days is the typical duration of the disease.

Immunofluorescence following a blood smear is the most common way to diagnose Colorado tick fever. Leukopenia and thrombocytopenia are other laboratory abnormalities associated with the disease. Presentation of symptoms and exposure to ticks should be an indicator of whether the patient is likely to have Colorado tick fever.

There is no specific medication indicated to treat Colorado tick fever. However, supportive treatment should be used. Tetracycline, doxycycline, and chloramphenicol are often prescribed to treat other potential tick-borne illnesses that the patient may have been exposed to.

\subsection{Ehrlichia}

Ehrlichiosis is contracted via tick borne vector. There are two common subtypes of ehrlichiosis in the United States that include human granulocytic ehrlichiosis (HGE) from Anaplasma phagocytophilum and human monocytic ehrlichiosis (HME) caused by Ehrlichia chaffeensis. These two subtypes are epidemiologically distinct but are clinically indistinguishable [27]. Southeastern and southcentral United States are more likely to expe- 
rience HME and typically affect adults. Northern and upper Midwestern United States is where the majority of HGE cases occur, particularly in adults that live in tick infested areas or in rural areas.

Flu like symptoms including fever, headache, myalgia, malaise, and chills. Other symptoms include petechial, macular, amulopapular rash in the upper extremities and the trunk with rarer occurrences in the palms and soles. These symptoms occur seven days after a tick bite. Although HME and HGE present similar signs and symptoms, the occurrence of a rash is remote for those infected with HGE. Differentiation between Rocky Mountain spotted fever and ehrlichiosis is difficult.

Elevated serum transaminase, leukopenia, and thrombocytopenia is evident in laboratory findings of patients with HME or HGE. Empirical treatment of patients experiencing nonspecific influenza like symptoms including fever, headache, myalgia, malaise, and chills in addition to leukopenia and thrombocytopenia should occur immediately. Seroconversion during convalescence is the principal method of diagnosing human ehrlichiosis. Serum antibody titers that are considered to be greater have values either equal to or greater than 1:128 or antibody titers with a minimum peak of 1:64 associated with a four-fold rise or fall in antibody titers.

Treatment with antibiotics should occur immediately after a diagnosis of ehrlichiosis. In adults, a dosage of $100 \mathrm{mg}$ twice per day of Docycline is recommended. An alternative treatment may include $500 \mathrm{mg}$ of tetracycline orally four times per day. Aplastic anemia is a risk of using chloramphenicol as an alternative to also prevent tooth decay. Although severe cases may require a longer treatment course, treatment should last for a minimum of five to seven days and should continue three days after fever subsides.

\subsection{Mycoplasma}

Mycoplasma pneumoniae does not have national reporting or a surveillance system. The true size of the health problem is unknown but is estimated to be approximately 2 million cases of mycoplasma pneumoniae each year in the United States.

Although pneumonia only occurs in 3\% - 10\% of cases of mycoplasma pneumoniae infections, mycoplasma pneumoniae is the most important form of atypical pneumonia respectively [28]. Banal bronchitis [28], earaches, rhinitis, pharyngitis, and sinusitis [29] occur most often in infections with mycoplasma pneumoniae. Other less common symptoms include maculopapular exanthema, vesicular dermatitis, encephalitis, meningitis, myelitis, cranial neuropathy, and cerebellar ataxia. Hepatitis, pancreatitis, and arthritis have also been reported from those infected with mycoplasma pneumoniae.

Several weeks after the disease becomes positive, mycoplasma pneumoniae can be detected by serology which indicates the significance of seroconversion in the chronic disease course. Although difficult and allowing low sensitivity, detection of Mycoplasma pneumoniae by PCR or cell culture is possible but not a part of the traditional diagnostic criteria.

$500 \mathrm{mg}$ of azithromycin, $500 \mathrm{mg}$ of levofloxacin, or $400 \mathrm{mg}$ doxycycline once a day for two weeks or more is the recommended treatment for mycoplasma pneumoniae.

\subsection{Powassan Virus}

Powassan virus is a Flavidridae virus that infects the nervous system. Flavidridae viruses are RNA viruses whose family is comprised of three genera including Flavivirus, Pestivirus, and Hepacivirus. Although the first documented case of Powassan virus occurred in the town of Powassan in Canada, Powassan has been reported in California, Connecticut, Maine, Massachusetts, New York, South Dakota, Vermont, West Virginia, and Wisconsin [11] [30]-[35]. The virus is transmitted via tick vector and infections usually occur during the summer and fall months.

Neuroinvasive syndromes, including encephalitis, meningitis, and myelitis, are the most common clinical presentation of the Powassan virus infection. Other nonspecific symptoms including fever, sore throat, somnolence, myalgia, head ache, dizziness, nausea, vomiting, lethargy, and malaise. The incubation period for Powassan virus is between 7 to 34 days [36]-[42].

Diagnosis of a Powassan viral infection can be difficult. In the majority of cases, analysis of cerebrospinal fluid (CSF) indicates a lymphocytic pleocytosis of less than $500 / \mathrm{mm}^{3}$. Generalized slow wave activity in patients with encephalitis can be revealed by electroencephalography of patients infected by Powassan virus. In three cases, isolation of Powassan virus from postmortem brain tissue was successfully recovered. There are no commercially available diagnostic method available for the detection of Powassan virus.

Treatment of Powassan infections are supportive since there is no specific antiviral therapy available. In most 
patients, anticonvulsant therapies have been enacted as well as the use of mechanical ventilation. Since Powassan virus can only be transmitted via tick bite, prevention is mostly centered around measures to avoid exposure to ticks.

\subsection{Q Fever}

The most common mode of Cociella burnetii is not through a tick but from exposure to infected cattle, particularly during birth. Western and plains states have a higher incidence of Q Fever than in other parts of the United States. Areas with a large amount of cattle ranching, sheep, and goat also have higher incidence rates for other states. Alaska and Hawaii have not had an incident of Q Fever. However, California, Colorado, Illinois, Kentucky, Missouri, Tennessee, and Texas account for over half of all human Q fever incidences. Although incidences of Q fever can happen throughout the year, the most common months of people acquiring with $\mathrm{Q}$ fever are during the spring and early summer months; peaking in April and May.

More than half of all people who contract Q fever do not experience any symptoms. However, symptoms including severe fever, headache, chills, and fatigue are common for acute infections. Another major clinical manifestation is atypical pneumonia. Some patients experience hepatitis as a result of an infection of Cociella burnetii. Myocarditis, pericarditis, skin rash, and meningoencephalitis are rare but can occur if infected.

Diagnosis of Q fever using immunohistology is the most common method. These techniques can include ELISA/ELIFA or immunofluorescence. Detection of Cociella burnetii must take place two to three weeks after contracting the disease. Culturing Cociella burnetii is a far less common method of detection due to the danger and risk of transmission to laboratory workers in addition to the lack of sensitivity using this technique.

Doxycycline and tetracycline are recommended for treatment of $\mathrm{Q}$ fever since the use of other antibiotics puts patients at a higher risk of severe illness. Of these two treatments, doxycycline is the most powerful and is the recommended mode of treating $\mathrm{Q}$ fever. Adults should take $100 \mathrm{mg}$ twice a day for three days after the fever subsides. Children should take $2.2 \mathrm{mg} / \mathrm{kg}$ per body weight of doxycycline with similar duration as in adults. The typical duration period is between two to three weeks.

\subsection{Relapsing Tick Fever}

A spirochete in the genus Borrelia is responsible for relapsing tick fever. The bacteria is transmitted via tick bite. Exposure to rabbits, rats, mice, squirrels, and chipmunks that harbor the tick associated with relapsing tick fever, particularly west of the Mississippi river in the more mountainous regions, are likely the source of relapsing tick fever. Small or sporadic clusters of the disease occur in this region.

One week after a tick bite is the average incubation period. Symptoms include dizziness, nausea vomiting, arthralgias, and influenza like symptoms. High fevers, which are fevers greater than $40^{\circ} \mathrm{C}\left(104^{\circ} \mathrm{F}\right)$, tend to be irregular and sporadic and may also be coupled with delirium. Splenomegaly is common for most patients with relapsing tick fever. Hemoptysis, iridocyclitis, cranial nerve palsy, myocarditis, rupture of spleen, epistaxis, coma, and pneumonitis are complications that can occur.

Blood, cerebral spinal fluid, or bone marrow during a febrile episode are the easiest way to detect the spirochete. Elevations in leukocyte count and thrombocytopenia are other laboratory findings that indicate the diagnosis of relapsing tick fever.

$100 \mathrm{mg}$ of doxycycline twice per day for ten days is the treatment of choice. $500 \mathrm{mg}$ of erythromycin four times a day for ten days is an alternative means of treating relapsing tick fever [43]. If given during the late febrile stage in particular, Jarisch-Herxheimer reaction can occur. A means to reduce this reaction can involve the use of acetaminophen two hours before the administration of antibiotics.

\subsection{Rocky Mountain Spotted Fever}

Rocky Mountain spotted fever is the most common rickettsial disease in the United States [44]. It is caused by an infection called Rickettsia rickettsi and occurs in every state in the US with the exception of Maine, Hawaii, and Alaska. Although infections can occur year round, particularly in southern states, the disease is most common in Atlantic states during the months between April and September [45]. Transmission through tick is the primary vector and there is no evidence to support that it can be transmitted from person to person. Children between five and nine years old have the highest incidence of contracting Rocky Mountain spotted fever [46].

Those that are infected by Rocky Mountain spotted fever recall a tick bite in $50 \%-70 \%$ of patients [47] [48]. 
Five to seven days after inoculation of Rickettsia rickettsi is when patients begin to feel the symptoms of Rocky Mountain spotted fever. Malaise, myalgias, nausea, vomiting, headache, and fever are the most common symptoms of Rocky Mountain spotted fever. Sore throat, pleuritic chest pain, non-productive cough, and abdominal pain are also experienced by infected patients. There is also potential for neurologic compromise in addition to circulatory and respiratory failure in patients [47]. High risk patients are those who have glucose-6-phosphatedhydrogenase (G6PD) deficiencies and often lead to poor outcomes and complications [48]. The appearance of lesions on the wrist, ankles, soles, palms, and forearms are macular, pink, and often fade when pressure is applied to them. After time, the rash then becomes maculopapular and later petechial and begins to appear on the buttocks, neck, face, trunk, and axilla [49]. Ecchymosis and ulcerations may appear as the lesions begin to coalesce.

Clinical signs and symptoms are the primary means of diagnosing Rocky Mountain spotted fever. Although skin biopsies and immuneflorescence is highly specific, the sensitivity is approximately $60 \%$. Bocytopenia and hyponatremia laboratory testing has limited usefulness [50]. During the convalescence period, latex agglutination titers and enzyme-linked immunosorbent assay (ELISA) can also be used for diagnostic purposes.

Early treatment during the course of the illness is important to obtain optimal effects and treatment should begin immediately when clinical and epidemiologic findings support the suspicion of Rocky Mountain spotted fever. A minimum of seven days treatment of chloramphenicol (Chloromycetin), tetracycline, and doxycycline (Vibramycin) can be used to treat Rickettsia rickettsi infections [51]. Evidence is lacking for the use of fluoroquinolones to treat Rocky Mountain spotted fever.

\subsection{Tularemia}

Tularemia, also known as rabbit fever, is caused by a bacteria known as Francisella tularensis. Southcentral, south eastern, and western United States are areas endemic of the tick vector associated with tularemia. Inoculation, contamination, inhalation, and ingestion of the bacteria is the most common form of transmission. Hunters who have skinned infected rabbits during the winter are the most common for transmission via microlesions. Transmission via tick vector is most common in the summer time but it should be noted that the disease can also spread through deer flies and horse flies. Infections can also be caused by contaminated water or consumption of infected meat even though these modes of transmission are rare.

Ulceroglandualr, oropharyngeal/gastrointestinal tract, ocularglandular, pulmonary, and typhoid tularemia are the clinical manifestations that are divided into syndromes [50]. Fever, malaise, fatigue, headache, myalgias, and headache occur rapidly after three to five days after inoculation with cough occurring in nearly one third of patients. Skin ulcers, pneumonia, nausea, vomiting, pericarditis, acute respiratory distress syndrome and sore throat are other symptoms that can occur. With the exception of glandular or typhoidal tularemia, inflammation of papules appear at the infected site. Ulcer craters with colorless exudate are seen when the papules become pustular and begin to ulcerate. Children are more likely to experience cervical or posterior auricular node infections. Femoral and inguinal nodes in adults are more likely to be affected.

Exposure to ticks, wild rodents, and rabbits with primary pustular lesion on an extremity should indicate tularemia. Although dangerous since the animal is likely to be infected, isolation of the organism from sputum, lymph nodes, or skin lesions can be used as a diagnostic tool. Culture media and infected tissue should be handled with extreme caution and doctors should be aware that the disease is considered a potential biological weapon. The diagnosis can also be confirmed by acute and convalescent titers. Although white blood cell count may be normal, leukocytosis is common. Tularemia can be differentiated from other tick-borne diseases by examining chest radiographs to see abnormal findings which include pleural effusions, hilar adenopathey, and a triad of oval opacities.

Before confirmation of laboratory tests, treatment should begin if tularemia is suspected. $0.5 \mathrm{~g}$ of streptomycin should be administered intermuscularly until the patient's fever is reduced to normal body temperature. Streptomycin should be used for five days after the fever subsides. Intravenous or intramuscular administration of gentamicin in three divided doses for seven to 14 days is another effective treatment option [52]. Gentamicin should be reduced if renal disease is present. The potential for relapse and prevention of node suppuration may occur if tetracyclines or chloramphenicol is used.

\section{Secondary Co-Infections or Common Opportunistic Infections}

Often asymptomatic infections can become symptomatic following an infection of Borrelia burgdorferi or ex- 
acerbated by the co-infections associated with chronic Lyme disease complex. In addition to weakening of the patient's immune system from the long exposure to tick borne infections, patient will commonly present several secondary co-infections. Treatment of these opportunistic infections are necessary but may also be a burden on patients already seeking treatment. The following list cannot be exhausted since there are too many potential secondary co-infections that can be listed in a single article. However, the following infections are observed more frequently in patients with Lyme disease complex.

\subsection{Candida Albicans}

Candida albicans has a $16 \mathrm{MB}$ genome consisting of eight pairs of chromosomal homologs that range in size from approximately 0.95 to $3.3 \mathrm{MB}$ and has a high level of genome plasticity in addition to its ability to lose heterozygosity. Candida albicans is one of two Candida species that can form true hyphae and has the capability of growing as either a yeast or filamentous form. It is a dimorphic species whose hyphae is integral in both adhesion and tissue invasion.

Candidiasis has three primary characteristics which include thrush, yeast infection, and invasive candidiasis. Thrush describes a Candida infection of the mouth and throat with the most common manifestation as oral thrush which is characterized by plaques on the tongue. Other symptoms associated with thrush include angular cheilitis, difficulty swallowing, and redness or soreness in affected areas including oral mucous membranes. Symptoms of a yeast infections include the hallmark abnormal vaginal discharge which can range from a thick, white, and clumpy cottage cheese like secretion or a slightly watery white discharge. The vagina and labia can become itchy with a burning sensation. Painful intercourse and painful urination were also common. The vulva can also become red and swollen. Invasive candidiasis often manifests itself similarly to many bacterial infections with fever and chills being the most predominant symptoms. Quite often patients prescribed antibiotics and do not improve later find that they actually have invasive candidiasis.

There are several different methods of diagnosing Candida albicans. The most predominant means of diagnosis remains blood culture (BC) which has a sensitivity between $30 \%$ and $50 \%$ and requires long incubation periods [53]. Patients undergoing fluconazole prophylaxis or have deep-seated candidiasis often have negative results using blood culture as a diagnostic criteria [54] [55]. The detection of mannan antigen on the cell wall of Candida albicans can be utilized by either a latex agglutination test and ELISA with specificity of $90 \%-100 \%$ for both tests [56] [57]. The sensitivity for ELISA is better with its sensitivity ranging between $30 \%-60 \%$. Detection of Candida albicans nucleic acid using PCR is significant particularly in deep-seated candidiasis with negative BCs since the sensitivity is $88 \%$ as compared to $17 \%$ for BCs [54].

There are several available treatment options for Candida Albicans that include either creams, tablets, or vaginal suppository. $5 \mathrm{~g}$ of Butoconazole $2 \%$ cream can be administered for a three day period or as one $2 \%$ suppository. Clotrimazole can be given as a cream or vaginal tablet. The $1 \%$ Clotrimazole cream can be administered in $5 \mathrm{~g}$ for seven to fourteen days and the $10 \%$ cream can be given as a $5 \mathrm{~g}$ single application. $100 \mathrm{mg}$ Clotrimazole tablet is given once a day for seven days or two tablets for three days. The $500 \mathrm{mg}$ dose of Clotrimazole requires only one tablet. $150 \mathrm{mg}$ of Econazole vaginal tablet can be administered once a day for three days. Fenticonazole comes as a $2 \%$ cream and should be administered in $5 \mathrm{~g}$ dosages for seven days. $2 \%$ cream of Tioconazole in $5 \mathrm{~g}$ dosages can be administered for three days. Terconazole can be administered as either a cream or a vaginal tablet. $5 \mathrm{~g}$ of $0.4 \%$ Terconazole cream can be administered for seven days while $5 \mathrm{~g}$ of $0.8 \%$ Terconazole cream is administered over a period of three days. An $80 \mathrm{mg}$ Terconazole as a vaginal suppository is administered over a period of three days. Fluconazole is a150 mg oral tablet that can be given as a single dose. Ketoconazole comes in a $200 \mathrm{mg}$ tablet that is taken twice a day for five days. $100 \mathrm{mg}$ tablet Itraconazole can be given twice a day for three days.

\subsection{Chlamydia pneumoniae}

Chlamydia pneumoniae is a Gram-negative bacteria which although has the genes to make peptidoglycan, the peptidoglycan is respectively undetectable, thus the chlamydial peptidoglycan paradox. Despite the autotrophic nature of Chlamydia pneumoniae, Chlamydia pneumoniae has genes associated with catabolize glucose for the generation of ATP even though these genes are turned off [58]. Elementary body (EB) and reticular body (RB) are morphologically distinct infectious and reproductive forms with unique developmental cycles. EBS are approximately $200-400 \mu \mathrm{m}$ in diameter and are taken into the cell via endocytosis post infection by a process involving electrostatic binding. EB remains in the phagosome within the host cell after endocytosis where fusion 
with lysosome does not occur. Binary fission occurs after EBs differentiate to RBs. Release involving either cytolysis or by exocytosis or extrusion of the entire inclusion occurs approximately $48 \mathrm{hr}$ later. The host cell remains intact during this process.

The clinical presentations of Chlamydia pneumoniae have significant variations and can range from mild disease to severe community acquired pneumonia (CAP). Although most patients are asymptomatic, lower and upper respiratory tract infections are common with pneumonia and bronchitis being the most common. Pharyngitis, laryngitis, and sinusitis are less common but can also occur in conjunction with a lower respiratory infection or in isolation. The incubation period of Chlamydia pneumoniae is approximately 21 days and is significantly longer than most other respiratory infections. Initial symptoms can include sore throat, hoarseness, or rhinitis. Myalgia and chills may also be accompanied with a fever with these symptoms subsiding in the period of days or weeks. A cough is the predominant symptom of a Chlamydia pneumoniae infection which can lead to a protracted biphasic course of illness symptoms. Severe symptoms have been reported for those that experience neutropenia as a result of treatment or patients with acute leukemia.

Culturing Chlamydia pneumoniae from an infected patient is the reference starting point for diagnosis of the infection. Nasopharyngeal swabs are used to collect samples since Chlamydia pneumoniae is an obligate intracellular organism and these cells must be collected from host cells that can host that environment. The samples are then cultured in vitro. Microimmunofluorescence (MIF) and enzyme immunoassays are the most common form of serological assays performed for the diagnosis of Chlamydia pneumoniae.

Tetracycline, erythromycin, doxycycline are agents used particularly for acute infections while antibiotics like ampicillin, penicillin, and sulfa drugs should not be used since Chlamydia pneumoniae can gain resistance to those antibiotics. $500 \mathrm{mg}$ of tetracycline four times a day for two weeks, $500 \mathrm{mg}$ of erythromycin four times a day for two weeks, or $100 \mathrm{mg}$ of doxycycline twice a day for three weeks are the best treatments for Chlamydia pneumoniae infections.

\subsection{Cytomegalovirus}

Cytomegalovirus (CMV) is a $230 \mathrm{~kb}$ double-stranded DNA virus and a member of the Herpesviridae family. A tegument, an icosahedron capsid, and an outer envelope surround the CMV DNA. The nuclear and cytoplasmic membrane of the host cell are components that are used to comprise the outer envelope. Three distinct viral glycoprotein complexes found in the outer envelope include gCI, gCII, and gCIII. Although the functions of these viral glycoprotein complex families are for the most part unknown, they are thought to be involved in viral attachment since antibodies to these glycoproteins block infectivity.

CMV is a primarily asymptomatic infection. However, symptomatic CMV can occur in the immunosuppressed depending on the severity of immune suppression. Symptoms include malaise (similar to that of Epstein-Barr virus), fever, myalgia, pharyngitis or skin disease, and lymphocytiosis.

CMV cannot be diagnosed on clinical presentation alone with the exception of retinitis. The diagnosis of CMV is more complex than viral isolation from patients. This is particularly true for immunosuppressed patients. Recently, the detection and diagnosis of CMV has been enhanced by monoclonal antibody technology in particular. Viral culture has been the traditional method of the diagnosis of CMV but has a turnaround time of approximately one to three weeks. Polymerase chain reaction (PCR) and nucleic acid probe methods have a higher sensitivity than cell cultures since cell cultures have the capability of creating false negatives. Antigen detection of CMV was discovered in the late 1990s and detects CMV pp 65 in circulating leukocytes before they are washed, fixed, and stained with monoclonal fluorescein or a peroxidase conjugate.

The prodrug for ganciclovir, known as valganciclovir, is activated in the liver and gut with $60 \%$ bioavailability. Intravenous ganciclovir $5 \mathrm{mg} / \mathrm{kg}$ is clinically equivalent to $900 \mathrm{mg}$ of valganciclovir taken one daily. However, $900 \mathrm{mg}$ of valganciclovir has side effects including leucopenia and has twice the likelihood of being rejected [59] [60].

\subsection{Epstein Barr Virus}

Epstein Barr Virus (EBV) is a herpes virus and therefore has characteristics that include double stranded linear DNA [61]. The capsid of EBV is an icosadeltahdron consisting of 162 capsomers surrounded by an envelope [61]. The receptor CD21 is primarily responsible for infection of B cells, causing continuous cell proliferation. This continuous cell proliferation can cause immortalization of B cells. During this process, there are several 
EBV related proteins that can be found within infected B cells. In the nucleus of infected B cells, initiating events which lead to proliferation associated with cellular DNA synthesis occurs in addition to the formation of EBV-determined nuclear antigens (EBNAs). Although the function of EBNAs remains primarily unknown, there are six different proteins that comprise the EBNA which include EBNA-1, EBNA-2, EBNA-3A, EBNA3B, EBNA-3C, and leader protein [61].

The clinical manifestation of an acute EBV infection (mononucleosis) includes fever, fatigue, cervical lymph node enlargement, and pharyngitis. Two clinical presentations that prevail in EBV infections include a sore throat and the development of malaise, myalgia, and fatigue. Adolescent and young adults in developed countries are more likely to contract mononucleosis but the reasoning behind this is not entirely understood.

Diagnosing mononucleosis cannot rely on symptoms alone. Heterophile antibody test is the practical way of diagnosing an EBV infection. Mammalian erythrocyte from various species are used in the heterophile tests in order to detect IgM class antibodies. This method of detecting EBV has its drawbacks since it is not likely to find EBV in patients 4 years or younger since they have not developed heterophile antibodies. Heterophile antibodies are also not very specific and can lead to false positives since other infections, malignancies, and autoimmune disease can lead to similar results as an EBV infection. VCA IgM, VCA IgG and EBNA-1 IgG specific antibody tests measured primarily from enzyme immunoassay platform are more specific than the heterophile antibody test. Reports of false positives have occurred using this assay [62]. It is important to note that EBNA-1 antibodies are not produced on the onset of the EBV infection and usually occur at 90 days or longer.

Although there is no definitive treatment for an EBV infection, there is some literature suggesting an off label use of acyclovir. The course of treatment is unknown and to our knowledge there are no drugs currently in the pipeline to treat $\mathrm{EBV}$ infections.

\subsection{Human Herpes Virus 6}

Human herpes virus 6 (HHV-6) is a member of the $\beta$-herpesvirus subfamily within the Roseolovirus genus and are divided into either HHV-6A or HHV-6B variants. The morphological features are similar to other herpes virion particles with a size ranging from $160 \mathrm{~nm}$ to $200 \mathrm{~nm}$. The genome of HHV-6A can range from $159 \mathrm{kbp}$ to $170 \mathrm{kbp}$ in length while the genome for HHV-6B is about $162 \mathrm{kbp}$ in length. The homology of HHV-7 is similar to that of HHV-6 with the exception of three genes which are specific to HHV-6; U22, U83, and U94. Differences between HHV-6A and HHV-6B include restriction endonuclease cleavage sites, properties associated with variation in tropism in vitro, and specificity of monoclonal antibodies given the difference in epitopes [63]-[65].

Most patients contract HHV-6 at an early age and primary infections in adulthood are rare. Roseola infantum is characterized by a maculopapular rash on the infant's trunk and neck with fever that last for approximately 3 5 days with temperatures often reaching $102^{\circ} \mathrm{F}-104^{\circ} \mathrm{F}$. In adults with primary infections a patient can experience mononucleosis-like fatigue in addition to elevated liver enzymes ( 1 - 3 weeks $)$, sore throat, and cervical lymphadenopathy [66] [67]. Other serious illnesses in adults can include fulminant hepatitis and meningoencephalitis [68]. HHV-6 can become reactivated in the immunocompromised. This usually causes patients to have increased antibody titers and a higher level of DNA retrieved via PCR but tend to be asymptomatic. Other patients are likely to experience mild illness with the presentation of a rash and a mild fever [69]-[71].

Methods for detecting the presence of HHV-6 including indirect serological approach or the direct approach have their advantages and disadvantages. Indirect serology involves IFA, ELISA, and avidity assays. An advantage to these methods includes the ease of use and the accessibility of these techniques. A disadvantage includes a cross-reactivity with other betaherpesviruses, the inability to distinguish between HHV-6A and HHV-6B, and delayed response in the immunocompromised. Direct methods include viral cell culture, antigen detection, and various PCR methods. Advantages for cell culture include direct evidence of infectious virus and the ability to engage in precise investigation of the strain of the virus. Disadvantages include limited sensitivity, high cost, and a more labor intensive method compared to all other direct and indirect methods. The advantages to antigen detection include being able to differentiate from HHV-6A and HHV-6B, provide evidence of the gene expression of the virus, and the equipment used is conventional. Limited sensitivity and ambiguity of current standards for the approach are some of the disadvantages of antigen detection. PCR methods for detecting and distinguishing HHV-6A and HHV-6B tend to be highly sensitive and specific. However, these methods can have limitations in distinguishing between active and latent since specific thresholds for active and latent infections are ambiguous.

Treatment for HHV-6 with acyclovir for immunocompetent patients is $400 \mathrm{mg}$ orally every 8 hours for seven 
to fourteen days. IV acyclovir involves a $5 \mathrm{mg} / \mathrm{kg}$ dose every eight hours for seven to fourteen days. For patients who experience episodic outbreaks, $200 \mathrm{mg}$ of acyclovir every four hours is recommended for seven to fourteen business days. Phosphonoformic acid can be used off label and may involve a $60 \mathrm{mg} / \mathrm{kg} / \mathrm{dose}$ at a constant rate for over at least one hour for every eight hours for two to three weeks. Cidofovir can also be used off label at 5 $\mathrm{mg} / \mathrm{kg} \mathrm{IV}$ infusion once a week for two consecutive weeks before a maintenance dose of $5 \mathrm{mg} / \mathrm{kg}$ IV infusion once every two weeks.

\subsection{Streptococcus pyogenes}

Streptococcus pyogenes is characterized as Gram-positive catalase-negative aerobic bacterium that is arranged in chains. The M protein on its outer layer reacts with various host proteins, inhibits the deposition of complements, has a pro-inflammatory response, and contributes to mucosal adhesion [72]. The genome of Streptococcus pyogenes is highly plastic. Intragenic and intergenic recombination associated with horizontal gene transfer has been observed and is of particular interest with regard to emm gene diversity [73].

It is important to differentiate symptoms of a Streptococcus pyogenes infection to that of a viral infection. Symptoms of Streptococcus pyrogene infections include fever, sore throat, tonsillitis, cervical lymphadenopathy, and tonsillar exudate. Other symptoms that can persist include headache, abdominal pain, nausea and vomiting, scarlet fever, loss of appetite, and general discomfort. Viral infections can have co-occurring symptoms including a runny nose, cough, hoarseness, eye redness, muscle aches, and diarrhea.

Laboratory tests should be the primary means of diagnosing a Streptococcus pyrogene infection since the clinical presentation is nonspecific. The two predominant methods of diagnosis involve either a throat culture or a rapid antigen-detection test from a specimen captured by a throat swab. The results of culturing Steptococcus pyrogene from a throat swab take approximately one to two days before a conclusive finding can be accepted respectively. Although rapid antigen-detection is significantly more expensive to run, the results of the test are significantly faster and can be obtained within minutes.

Treatment of Streptococcal pharyngitis often relies on the use of penicillin and its derivatives. $500 \mathrm{mg}$ of Penicillin $\mathrm{V}$ two or three times a day for ten days or $50 \mathrm{mg} / \mathrm{kg}$ of Amoxicillin (with a maximum of $1 \mathrm{~g}$ ) once a day for ten days are the predominate method of treating Streptococcal pharyngitis. Patients with allergies to penicillin and its derivatives should take either Cephalexin, Cefadroxil, Azithromycin, or Clindamycin. $20 \mathrm{mg} / \mathrm{kg} / \mathrm{dose}$ of Cephalexin taken orally twice daily for 10 days, $30 \mathrm{mg} / \mathrm{kg}$ of Cefadroxil once a day for 10 days, $12 \mathrm{mg} / \mathrm{kg}$ of Azithromycin once a day for 5 days, or $7 \mathrm{mg} / \mathrm{kg} /$ dose of Clindamycin three times a day for 10 days are the recommended dosages for treating Streptococcal pharyngitis. Maximum tolerated dosages do apply to each of these medications and therefore careful consideration should be taken for individuals with higher weights.

\section{Mycotoxin}

Although exposure to mycotoxins is rare in patients with chronic Lyme disease complex, there have been several instances where patients being treated for Lyme disease have also been exposed to mycotoxins. As the name suggest, mycotoxins are toxic secondary metabolites produced by a few fungal species that are known to colonize crops. The amount of species of fungi that produce mycotoxins is vast and therefore not listed independently. Instead, various mycotoxins are listed with their effect on the mammalian system as well as the methods for detecting the mycotoxins in various matrices of contaminated food. The word mycotoxin stems from the Greek word "myke" which means fungus and the Latin word "toxicum" which means poison. Secondary metabolites of fungus are not always harmful. Significant advances in the treatment of bacterial infections stemmed from secondary metabolites of fungal species. However, there are several mycotoxins that have a major negative effect on humans.

Mycotoxins are characterized by their small molecular weight ranging around a MW of 700 . The structural and chemical diversity of mycotoxins are vast. The majority of mycotoxins are a result of chemical reactions associated with metabolites including acetates and pyruvates in particular. Such diversity also leads to varying levels of toxic effects that can be either acute or chronic. Contamination of mycotoxins can occur before harvest or after harvest. This is particularly true for plants that have been stored for more than a few days. Commonly contaminated food includes dried fruit, coffee, spices, cocoa, oil seeds, beans, dried peas, cereal, nuts, and apples in particular. More information regarding the methods of detecting mycotoxins in various food sources can be seen in Table 1 . 
Table 1. The table below is a list of common mycotoxins, their effect on the mammalian system, where the mycotoxins can be found, and the protocol for a method of detecting the mycotoxins within a matrix.

\begin{tabular}{|c|c|c|c|c|}
\hline Toxin & $\begin{array}{l}\text { Major effects on mammalian } \\
\text { systems }\end{array}$ & Protocol & Matrix & Reference \\
\hline Aflatoxins & $\begin{array}{l}\text { Acute hepatitis, impaired immune } \\
\text { system, carcinogenic }\end{array}$ & UV-HPLC & Brazilian peanut kernels & {$[74]-[78]$} \\
\hline Citrinin & Nephrotoxic & $\begin{array}{l}\text { Time resolved luminescence } \\
\text { (TRL) }\end{array}$ & Soft cheese & {$[79][80]$} \\
\hline Moniliformin & $\begin{array}{c}\text { Weight loss, intestinal } \\
\text { hemorrhage, Keshan disease }\end{array}$ & Normal-HPCL & Cereals & [80]-[84] \\
\hline Ochratoxin A & $\begin{array}{l}\text { Carcinogenic, hepatotoxic, } \\
\text { teratogenic, nephrotoxic }\end{array}$ & $\begin{array}{l}\text { Membrane based flow through } \\
\text { enzyme immunoassay }\end{array}$ & Cereals & [74] [85] \\
\hline Patulin & Lung and brain haemorrhaging & $\begin{array}{l}\text { Micoremulsionelectrokinetic } \\
\text { chromatography (MEECK) }\end{array}$ & Commercial apple juice & {$[86][87]$} \\
\hline Trichothecene & $\begin{array}{c}\text { Gasroinestinalhaemorrhaging, } \\
\text { immuno-depressant }\end{array}$ & $\begin{array}{l}\text { HPLC analysis after supercritical } \\
\text { fluid extraction (SFE) }\end{array}$ & Wheat & [88]-[91] \\
\hline Zeralenone & Estrogenic Activity & Normal-HPCL & Cereals & {$[92]$} \\
\hline
\end{tabular}

\section{Discussion}

It is critical to treat Lyme disease at its early stages since Borrelia burgdorferi has the potential to protect itself from antibiotics and the immune system through various mechanisms if given ample time to spread throughout the body. Many patients do not recall getting bit by a tick and many patients do not receive the characteristic bull's eye skin formation. The diagnostic criteria for detecting Borrelia can also be problematic. This leads to patients obtaining chronic Lyme disease that is not easily treated by antibiotics alone. To make things worse, many patients experience symptoms associated with co-infections and secondary co-infections.

Awareness of doctors to quickly recognize the symptoms of Lyme disease as well as the awareness to differentiate the symptoms associated with co-infections is critical. Improper diagnosis or even partial diagnosis of Lyme disease and their associated co-infections can lead to serious complications that can lead to hospitalization and even death. Powassan virus in particular is of concern since there is no readily available method to diagnose or treat the disease. More research is absolutely needed for the Powassan virus since even the most fundamental aspects of the Powassan virus remain a mystery.

The most common co-infections, including anaplasmosis, babesiosis, bartonellosis, and ehrlichiosis, are all treatable with antibiotics. However, although treatment is necessary and can be safely administered, the additional antibiotics to treat these co-infections of Lyme disease is an additional burden on the body. These co-infections are significantly easier to treat than chronic Lyme disease but it is important to note that the health of the patient is significantly worse than those with only Lyme disease. It is important to not only recognize and diagnose the co-infections but to also treat the root of their disease rather than treating the symptoms.

\section{Conclusion}

The list of secondary co-infections is not by any means exhaustive. Opportunistic infections can occur with or without additional co-infections to patients with chronic Lyme disease, further complicating treatment. It is important to monitor patients with Lyme disease in order to reduce the likelihood of contracting an opportunistic infection including diagnosing and treating previously asymptomatic diseases if and when they occur. Complications such as exposure to mycotoxins highlight the significance of being aware of various factors that can impact a patient's health that is not usually associated with Lyme disease. Chronic Lyme disease patients also need immune system monitoring to help maintain long term immune surveillance and to decrease the re-occurrence of these infections.

\section{References}

[1] Bakken, J.S., Goellner, P., Van Etten, M., et al. (1998) Seroprevalence of Human Granulocytic Ehrlichiosis among Permanent Residents of Northwestern Wisconsin. Clinical Infectious Diseases, 27, 1491-1496. http://dx.doi.org/10.1086/515048 
[2] Bakken, J.S., Dumler, J.S., Chen, S.M., et al. (1994) Human Granulocytic Ehrlichiosis in the Upper Midwest United States: A New Species Emerging? JAMA, 272, 212-218. http://dx.doi.org/10.1001/jama.1994.03520030054028

[3] Aguero-Rosnfeld, M.E., Horowitz, H.W., Wormser, G.P., et al. (1996) Human Granulocytic Ehrlichiosis: A Case Series from a Medical Center in New York State. Annals of Internal Medicine, 125, 904-908. http://dx.doi.org/10.7326/0003-4819-125-11-199612010-00006

[4] Blanco, J.R. and Oteo, J.A. (2002) Human Granulocytic Ehrlichiosis in Europe. Clinical Microbiology and Infection, 8, 763-772. http://dx.doi.org/10.1046/j.1469-0691.2002.00557.x

[5] Bakken, J.S., Krueth, J., Wilson-Nordskog, C., et al. (1996) Clinical and Laboratory Characteristics of Human Granulocytic Ehrlichiosis. JAMA, 275, 199-205. http://dx.doi.org/10.1001/jama.1996.03530270039029

[6] Wallace, B.J., Brady, G., Ackman, D.M., et al. (1998) Human Granulocytic Ehrlichiosis in New York. Archives of Internal Medicine, 158, 769-773. http://dx.doi.org/10.1001/archinte.158.7.769

[7] Lepidi, H., Bunnel, J.E., Martin, M.E., et al. (2000) Comparative Pathology, and Immunohistology Associated with Clinical Illness after Ehrlichia phagocytophila group Infections. The American Journal of Tropical Medicine and Hygiene, 62, 29-37.

[8] Bakken, J.S., Erlemeyer, S.A., Kanoff, R.J., et al. (1998) Demyelinating Polyneuropathy Associated with Human Granulocytic Ehrlichiosis. Clinical Infectious Diseases, 27, 1323-1324. http://dx.doi.org/10.1093/clinids/27.5.1323

[9] Horowitz, H.W., Marks, S.J., Weintraub, M. and Dumler, J.S. (1996) Brachial Plexopathy Associated with Human Granulocytic Ehrlichiosis. Neurology, 46, 1026-1029. http://dx.doi.org/10.1212/WNL.46.4.1026

[10] Jahangir, A., Kolbert, C., Edwards, W., et al. (1998) Fatal Pancarditis Associated with Human Granulocytic Ehrlichiosis in a 44-Year-Old Man. Clinical Infectious Diseases, 27, 1424-1427. http://dx.doi.org/10.1086/515014

[11] Kuno, G., Artsob, H., Karabatsos, N., Tsuchiya, K.R. and Chang, G.J. (2001) Genomic Sequencing of Deer Tick Virus and Phylogeny of Powassan-Related Viruses of North America. The American Journal of Tropical Medicine and Hygiene, 65, 671-676.

[12] Horowitz, H.W., Hsieh, T.C., Aguero-Rosenfeld, M.E., Kalantarpour, F., Chowdhury, I., Wormser, G.P. and Wu, J.M. (2001) Antimicrobial Susceptibility of Ehrlichia phagocytophila. Antimicrobial Agents and Chemotherapy, 45, 786788. http://dx.doi.org/10.1128/AAC.45.3.786-788.2001

[13] Klein, M.B., Nelson, C.M. and Goodman, J.L. (1997) Antibiotic Susceptibility of the Newly Cultivated Agent of Human Granulocytic Ehrlichiosis: Promising Activity of Quinolones and Rifamycins. Antimicrobial Agents and Chemotherapy, 41, 76-79.

[14] Maurin, M., Bakken, J.S. and Dumler, J.S. (2003) Antibiotic Susceptibilities of Anaplasma (Ehrlichia) phagocytophilum Strains from Various Geographic Areas in the United States. Antimicrobial Agents and Chemotherapy, 47, 413415. http://dx.doi.org/10.1128/AAC.47.1.413-415.2003

[15] Bakken, J.S. and Dumler, J.S. (2000) Human Granulocytic Ehrlichiosis. Clinical Infectious Diseases, 31, 554-560. http://dx.doi.org/10.1086/313948

[16] Bakken, J.S. and Dumler, J.S. (2002) Ehrlichia and Anaplasma Species. In: Yu, V., Weber, R. and Raoult, D., Eds., Antimicrobial Therapy and Vaccine, Apple Trees Productions, LLC, New York, 875-882.

[17] Dumler, J.S. and Walker, D.H. (2001) Tick-Borne Ehrlichioses. The Lancet Infectious Diseases, 1, 21-28. http://dx.doi.org/10.1016/S1473-3099(09)70296-8

[18] Fishbein, D.B., Dawson, J.E. and Robinson, L.E. (1994) Human Ehrlichiosis in the United States, 1985 to 1990. Annals of Internal Medicine, 120, 736-743. http://dx.doi.org/10.7326/0003-4819-120-9-199405010-00003

[19] Olano, J.P. and Walker, D.H. (2002) Human Ehrlichioses. Medical Clinics of North America, 86, 375-392. http://dx.doi.org/10.1016/S0025-7125(03)00093-2

[20] Paddock, C.D. and Childs, J.E. (2003) Ehrlichia chaffeensis: A Prototypical Emerging Pathogen. Clinical Microbiology Reviews, 16, 37-64. http://dx.doi.org/10.1128/CMR.16.1.37-64.2003

[21] Carithers, H.A. (1985) Cat-Scratch Disease. An Overview Based on a Study of 1200 Patients. American Journal of Diseases of Children, 139, 1124-1133. http://dx.doi.org/10.1001/archpedi.1985.02140130062031

[22] Rolain, J.M., Lepidi, H., Zanaret, M., Triglia, J.-M., Michel, G., Thomas, P.-A., et al. (2006) Lymph Node Biopsy Specimens and Diagnosis of Cat-Scratch Disease. Emerging Infectious Diseases, 12, 1338-1344. http://dx.doi.org/10.3201/eid1209.060122

[23] Rolain, J.M., Brouqui, P., Koehler, J.E., Maguina, C., Dolan, M.J. and Raoult, D. (2004) Recommendations for Treatment of Human Infections Caused by Bartonella Species. Antimicrobial Agents and Chemotherapy, 48, 1921-1933. http://dx.doi.org/10.1128/AAC.48.6.1921-1933.2004

[24] Bass, J.W., Freitas, B.C., Freitas, A.D., Sisler, C.L., Chan, D.S., Vincent, J.M., et al. (1998) Prospective Randomized 
Double Blind Placebo-Controlled Evaluation of Azithromycin for Treatment of Cat-Scratch Disease. Pediatric Infectious Disease Journal, 17, 447-452. http://dx.doi.org/10.1097/00006454-199806000-00002

[25] Margileth, A.M. (1992) Antibiotic Therapy for Cat-Scratch Disease: Clinical Study of Therapeutic Outcome in 268 Patients and a Review of the Literature. Pediatric Infectious Disease Journal, 11, 474-478. http://dx.doi.org/10.1097/00006454-199206000-00010

[26] Emmons, R.W. (1985) An Overview of Colorado Tick Fever. Progress in Clinical and Biological Research, 178, 47-52.

[27] Belman, A.L. (1999) Tick-Borne Diseases. Seminars in Pediatric Neurology, 6, 249-266. http://dx.doi.org/10.1016/s1071-9091(99)80024-2

[28] Mansel, J.K., Rosenow III, E.C., Smith, T.F. and Martin Jr., J.W. (1989) Mycoplasma pneumoniae Pneumonia. Chest, 95, 639-646. http://dx.doi.org/10.1378/chest.95.3.639

[29] Martin, R.E. and Bates, J.H. (1991) Atypical Pneumonia. Infectious Disease Clinics of North America, 5, 585-601.

[30] Artsob, H. (1988) Powassan Encephalitis. In: Monath, T.P., Ed., The Arboviruses: Epidemiology and Ecology, Vol. 4 , CRC Press, Boca Raton, 29-49.

[31] Ebel, G.D., Spielman, A. and Telford III, S.R. (2001) Phylogeny of North American Powassan Virus. Journal of General Virology, 82, 1657-1665. http://dx.doi.org/10.1099/0022-1317-82-7-1657

[32] Gritsun, T.S., Nuttall, P.A. and Gould, E.A. (2003) Tick-Borne Flaviviruses. In: Chambers, T.J. and Monath, T.P., Eds., The Flavivirus: Detection, Diagnosis and Vaccine Development, Advances in Viral Research, Vol. 61, Elsevier Academic Press, San Diego, 318-324. http://dx.doi.org/10.1016/s0065-3527(03)61008-0

[33] Whitney, E. and Jamnback, H. (1965) The First Isolations of Powassan Virus in New York State. Experimental Biology and Medicine, 119, 432-435. http://dx.doi.org/10.3181/00379727-119-30202

[34] Main, A.J., Carey, A.B. and Downs, W.G. (1979) Powassan Virus in Ixodes cookie and Mustelidae in New England. Journal of Wildlife Diseases, 15, 585-591. http://dx.doi.org/10.7589/0090-3558-15.4.585

[35] Mahdy, M.S., Wilson, M., Wherrett, B. and Dorland, R. (1979) Powassan Virus (POWV) Encephalitis in Ontario: A Case of Meningoencephalitis Attributed to Infection with POWV in Eastern Ontario.

[36] Rossier, E., Harrison, R.J. and Lemieux, B. (1974) A Case of Powassan Virus Encephalitis. CMAJ, 110, 1173-1174.

[37] Smith, R., Woodall, J.P., Whitney, E., Deibel, R., Gross, M.A., Smith, V. and Bast, T.F. (1974) Powassan Virus Infection: A Report of Three Human Cases of Encephalitis. American Journal of Diseases of Children, 127, 691-693. http://dx.doi.org/10.1001/archpedi.1974.02110240077010

[38] Deibel, R., Srihongse, S. and Woodall, J.P. (1979) Arboviruses in New York State: An Attempt to Determine the Role of Arboviruses in Patients with Viral Encephalitis and Meningitis. The American Journal of Tropical Medicine and Hygiene, 28, 577-582.

[39] Wilson, M.S., Wherrett, B.A. and Mahdy, M.S. (1979) Powassan Virus Meningoencephalitis: A Case Report. CMAJ, 121, 320-323.

[40] Joshua, J.M. (1979) A Case of Powassan Virus Encephalitis Ontario. Canada Diseases Weekly Report, 5, 129-130.

[41] Centers for Disease Control and Prevention (1995) Arboviral Disease-United States, 1994. MMWR Morbidity and Mortality Weekly Report, 44, 641-644.

[42] Gholam, B.I., Puksa, S. and Provias, J.P. (1999) Powassan Encephalitis: A Case Report with Neuropathology and Literature Review. CMAJ, 161, 1419-1422.

[43] Gilbert, D.N., Moellering, R.C., Eliopoulos, G.M. and Sande, M.A. (2004) The Sanford Guide to Antimicrobial Therapy. 34th Edition, Antimicrobial Therapy, Hyde Park, 39.

[44] Byrd Jr., R.P., Vasquez, J. and Roy, T.M. (1997) Respiratory Manifestations of Tick-Borne Diseases in the Southeastern United States. Southern Medical Journal, 90, 1-4. http://dx.doi.org/10.1097/00007611-199701000-00001

[45] Beers, M.H. and Berkow, R. (1999) The Merck Manual of Diagnosis and Therapy. 17th Edition, Merck Research Laboratories, Whitehouse Station.

[46] Walker, D.H. (1998) Tick-Transmitted Infectious Diseases in the United States. Annual Review of Public Health, 19, 237-269. http://dx.doi.org/10.1146/annurev.publhealth.19.1.237

[47] Kwitkowski, V.E. and Demko, S.G. (1999) Infectious Disease Emergencies in Primary Care. Lippincott's Primary Care Practice, 3, 108-125.

[48] Centers for Disease Control and Prevention. Rocky Mountain Spotted Fever. Accessed Online 11 April 2005. http://www.cdc.gov/ncidod/dvrd/rmsf/index.htm

[49] Drage, L.A. (1999) Life-Threatening Rashes: Dermatologic Signs of Four Infectious Diseases. Mayo Clinic Proceed- 
ings, 74, 68-72. http://dx.doi.org/10.4065/74.1.68

[50] Steeve, A.C. (2005) Lyme Borreliosis. In: Kasper, D.L. and Harrison, T.R., Eds., Harrison's Manual of Medicine, 16th Edition, McGraw-Hill, New York, 995-999.

[51] Shapiro, E.D. (1997) Tick-Borne Diseases. Advances in Pediatric Infectious Diseases, 13, 187-218.

[52] Dennis, D.T., Inglesby, T.V., Henderson, D.A., Bartlett, J.G., Ascher, M.S., Eitzen, E., et al. (2001) Tularemia as a Biological Weapon: Medical and Public Health Management. JAMA, 285, 2763-2773. http://dx.doi.org/10.1001/jama.285.21.2763

[53] Mikulska, M., Calandra, T., Sanguinetti, M., Poulain, D. and Viscoli, C. (2010) The Use of Mannan Antigen and Anti-Mannan Antibodies in the Diagnosis of Invasive Candidiasis: Recommendations from the Third European Conference on Infections in Leukemia. Critical Care, 14, R222. http://dx.doi.org/10.1186/cc9365

[54] Nguyen, M.H., Wissel, M.C., Shields, R.K., Salomoni, M.A., Hao, B., Press, E.G., Shields, R.M., Cheng, S., Mitsani, D., Vadnerkar, A., et al. (2012) Performance of Candida Real-Time Polymerase Chain Reaction, Beta-D-Glucan Assay, and Blood Cultures in the Diagnosis of Invasive Candidiasis. Clinical Infectious Diseases, 54, 1240-1248. http://dx.doi.org/10.1093/cid/cis200

[55] Guery, B.P., Arendrup, M.C., Auzinger, G., Azoulay, E., Borges, S.M., Johnson, E.M., Müller, E., Putensen, C., Rotstein, C., Sganga, G., et al. (2009) Management of Invasive Candidiasis and Candidemia in Adult Non-Neutropenic Intensive Care Unit Patients: Part I. Epidemiology and Diagnosis. Intensive Care Medicine, 35, 55-62. http://dx.doi.org/10.1007/s00134-008-1338-7

[56] Ahmad, S. and Khan, Z. (2012) Invasive Candidiasis: A Review of Nonculture-Based Laboratory Diagnostic Methods. Indian Journal of Medical Microbiology, 30, 264-269. http://dx.doi.org/10.4103/0255-0857.99482

[57] Sendid, B., Tabouret, M., Poirot, J.L., Mathieu, D., Fruit, J. and Poulain, D. (1999) New Enzyme Immunoassays for Sensitive Detection of Circulating Candida albicans Mannan and Antimannan Antibodies: Useful Combined Test for Diagnosis of Systemic Candidiasis. Journal of Clinical Microbiology, 37, 1510-1517.

[58] Rockey, D.D., Lenart, J. and Sephens, R.S. (2000) Genome Sequencing and Our Understanding of Chlamydiae. Infection and Immunity, 68, 5473-5479. http://dx.doi.org/10.1128/IAI.68.10.5473-5479.2000

[59] Kalil, A.C., Mindru, C. and Florescu, D.F. (2011) Effectiveness of Valganciclovir $900 \mathrm{mg}$ versus $450 \mathrm{mg}$ for Cytomegalovirus Prophylaxis in Transplantation: Direct and Indirect Treatment Comparison Meta-Analysis. Clinical Infectious Diseases, 52, 313-321. http://dx.doi.org/10.1093/cid/ciq143

[60] Avery, R.K. (2011) Low-Dose Valganciclovir for Cytomegalovirus Prophylaxis in Organ Transplantation: Is Less Really More? Clinical Infectious Diseases, 52, 322-324. http://dx.doi.org/10.1093/cid/ciq145

[61] Okano, M. (1998) Epstein/Barr Virus Infection and Its Role in the Expanding Spectrum of Human Diseases. Acta Paediatrica, 87, 11-18. http://dx.doi.org/10.1111/j.1651-2227.1998.tb01377.x

[62] Guerrero-Ramos, A., Patel, M., Kadakia, K. and Haque, T. (2014) Performance of the Architect EBV Antibody Panel for Determination of Epstein-Barr Virus Infection Stage in Immunocompetent Adolescents and Young Adults with Clinical Suspicion of Infectious Mononucleosis. Clinical and Vaccine Immunology, 21, 817-823. http://dx.doi.org/10.1128/CVI.00754-13

[63] Campadelli Fiume, G., Guerrini, S., Liu, X. and Foà-Tomasi, L. (1993) Monoclonal Antibodies to Glycoprotein B Differentiate Human Herpesvirus 6 into Two Clusters, Variants A and B. Journal of General Virology, 74, 2257-2262. http://dx.doi.org/10.1099/0022-1317-74-10-2257

[64] Schirmer, E.C., Wyatt, L.S., Yamanishi, K., Rodriguez, W.J. and Frenkel, N. (1991) Differentiation between Two Distinct Classes of Viruses Now Classified as Human Herpesvirus 6. Proceedings of the National Academy of Sciences of the United States of America, 88, 5922-5926. http://dx.doi.org/10.1073/pnas.88.13.5922

[65] Ablashi, D.V., Balachandran, N., Josephs, S.F., Hung, C.L., Krueger, G.R. and Kramarsky, B. (1991) Genomic Polymorphism, Growth Properties, and Immunologic Variations in Human Herpesvirus-6 Isolates. Virology, 184, 545-552. http://dx.doi.org/10.1016/0042-6822(91)90424-A

[66] Niederman, J.C., Liu, C.-R., Kaplan, M.H. and Brown, N.A. (1988) Clinical and Serological Features of Human Herpesvirus-6 Infection in Three Adults. Lancet, 2, 817-819. http://dx.doi.org/10.1016/S0140-6736(88)92783-3

[67] Akashi, K., Eizuru, Y., Sumiyoshi, Y., Minematsu, T., Hara, S., Harada, M., et al. (1993) Brief Report: Severe Infectious Mononucleosis-Like Syndrome and Primary Human Herpesvirus 6 Infection in an Adult. New England Journal of Medicine, 329, 168-171. http://dx.doi.org/10.1056/NEJM199307153290304

[68] Torre, D., Speranza, F., Martegani, R., Ferrante, P., Omodeo-Zorini, E., Mancuso, R. and Fiori, G.P. (1998) Meningoencephalitis Caused by Human Herpesvirus-6 in an Immunocompetent Adult Patient: Case Report and Review of the Literature. Infection, 26, 402-404. http://dx.doi.org/10.1007/BF02770845

[69] Cone, R.W., Huang, M.-L., Corey, L., Zeh, J., Ashley, R. and Bowden, R. (1999) Human Herpesvirus 6 Infections af- 
ter Bone Marrow Transplantation: Clinical and Virologic Manifestations. The Journal of Infectious Diseases, 179, 311 318. http://dx.doi.org/10.1086/314581

[70] Herbein, G., Strasswimmer, J., Altieri, M., Jaegle, M.-L.W., Wolf, P. and Obert, G. (1996) Longitudinal Study of Human Herpesvirus 6 Infection in Organ Transplant Recipients. Clinical Infectious Diseases, 22, 171-173. http://dx.doi.org/10.1093/clinids/22.1.171

[71] Lau, Y.L., Peiris, M., Chan, G.C., Chan, A.C.L., Chiu, D. and Ha, S.Y. (1998) Primary Human Herpesvirus Infection Transmitted from Donor to Recipient through Bone Marrow Infusion. Bone Marrow Transplantation, 21, 1063-1067. http://dx.doi.org/10.1038/sj.bmt.1701230

[72] Oehmcke, S., Shannon, O., Mörgelin, M. and Herwald, H. (2010) Streptococcal M Proteins and Their Role as Virulence Determinants. Clinica Chimica Acta, 411, 1172-1180. http://dx.doi.org/10.1016/j.cca.2010.04.032

[73] Dowson, C.G., Barcus, V., King, S., Pickerill, P., Whatmore, A. and Yeo, M. (1997) Horizontal Gene Transfer and the Evolution of Resistance and Virulence Determinants in Streptococcus. Journal of Applied Microbiology, 26, 42S-51S. http://dx.doi.org/10.1046/j.1365-2672.83.s1.5.x

[74] IARC (1993) International Agency for Research on Cancer, Geneva, Vol. 56, 489.

[75] Goncalez, E., Nogueira, J.H.C., Fonseca, H., Felicio, J.D., Pino, F.A. and Corrêa, B. (2008) Mycoflora and Mycotoxins in Field Samples of Brazil Nuts. International Journal of Food Microbiology, 123, 184-190.

[76] Ellis, W.O., Smith, J.P. and Simpson, B.K. (1991) Aflatoxins in Food: Occurrence, Biosynthesis, Effects on Organisms, Detection, and Methods of Control. Critical Reviews in Food Science and Nutrition, 30, 403-439. http://dx.doi.org/10.1080/10408399109527551

[77] Ngindu, A., Johnson, B., Kenya, P.R., Ngira, J.A. and Ocheng, D.M. (1982) Outbreak of Acute Hepatitis by Aflatoxin Poisoning in Kenya. Lancet, 319, 1346-1348. http://dx.doi.org/10.1016/S0140-6736(82)92411-4

[78] Lye, M.S., Ghazali, A.A., Mohan, J., Alwin, N. and Nair, R.C. (1995) An Outbreak of Acute Hepatic Encephalopathy Due to Severe Aflatoxicosis in Malaysia. The American Journal of Tropical Medicine and Hygiene, 53, 68-72.

[79] Vazquez, B.I., Fente, C., Franco, C., Cepeda, A., Prognon, P. and Mahuzier, G. (1996) Simultaneous HPLC Determination of Ochratoxin A and Citrinin in Cheese by Time-Resolved Luminescence Using Terbium. Journal of Chromatography A, 727, 185-193. http://dx.doi.org/10.1016/0021-9673(95)01174-9

[80] Reddy, C.S. and Berndt, W.O. (1991) In: Sharma, R.P. and Salunkhe, D.K., Eds., Mycotoxins and Phyloalexins, CRC Press, Boca Raton, 237.

[81] Filek, G. and Lindner, W. (1996) Determination of Mycotoxin Moniliformin in Cereals by High-Performance Liquid Chromatography and Fluorescence Detection. Journal of Chromatography A, 732, 291-298. http://dx.doi.org/10.1016/0021-9673(95)01275-3

[82] D’Mello, J.P.F. and Macdonald, A.M.C. (1997) Mycotoxins. Animal Feed Science and Technology, 69, 155-166. http://dx.doi.org/10.1016/S0377-8401(97)81630-6

[83] Meerdink, G.L. (2002) Mycotoxins. Clinical Techniques in Equine Practice, 1, 89-93. http://dx.doi.org/10.1053/ctep.2002.34240

[84] Prieto-Simón, B., Noguer, T. and Campàs, M. (2007) Emerging Biotools for Assessment of Mycotoxins in the Past Decade. TrAC Trends in Analytical Chemistry, 26, 689-702. http://dx.doi.org/10.1016/j.trac.2007.05.012

[85] MAFF (1993) The 36th Report of the Steering Group on Chemical Aspects of Food Surveillance. Mycotoxins: Third Report. HMSO, London, 40

[86] Arbizu, M.M., Penas, E.G., Hansen, S.H., Amézqueta, S. and Ostergaard, J. (2008) Development and Validation of a Microemulsionelctrokinetic Chromatography Method for Patulin Quantification in Commercial Apple Juice. Food and Chemical Toxicology, 46, 2251-2257. http://dx.doi.org/10.1016/i.fct.2008.02.027

[87] McKinley, E.K. and Carlton, W.W. (1991) In: Sharma, R.P. and Salunkhe, D.K., Eds., Mycotoxins and Phyloalexins, CRC Press, Boca Raton, 191.

[88] EMAN (2003) European Mycotoxin Awareness Network Co-Ordinated by Leatherhead Food Research Association (UK). http://www.lfra.co.uk/eman/index.htm

[89] Frisvad, J.C. (1994) In: Hawksworth, D.L., Ed., Identification and Characterization of Pest Organisms, CAB International, Wallingford, 303.

[90] Josephs, R.D., Krska, R., Grasserbauer, M. and Broekaert, J.A.C. (1998) Determination of Tichothecene Mycotoxins in Wheat by Use of Supercritical Fluid Extraction and High Performance Liquid Chromatography with Diode Array Detection or Gas Chromatography with Electron Capture Detection. Journal of Chromatography A, 795, 297-304. http://dx.doi.org/10.1016/S0021-9673(97)00944-8

[91] D’Mello, J.P.F., Placinta, C.M. and Macdonald, A.M.C. (1999) Fusarium Mycotoxins: A Review of Global Implica- 
tions for Animal Health, Welfare and Productivity. Animal Feed Science and Technology, 80, 183-205. http://dx.doi.org/10.1016/S0377-8401(99)00059-0

[92] Tanaka, T., Hasegawa, A., Matsuki, Y., Lee, U.S. and Ueno, Y. (1985) Rapid and Sensitive Determination of Zearalenone in Cereal by High Performance Liquid Chromatography with Fluorescence Detection. Journal of Chromatography A, 328, 271-278. http://dx.doi.org/10.1016/S0021-9673(01)87397-0 